\title{
Perancangan E-Sport Arena di Kota Bandung dengan Penerapan Arsitektur Metafora
}

\author{
Algalif Abdul Aziz \\ Fakultas Teknik, Program Studi Arsitektur \\ Universitas Langlangbuana \\ algalifabdulaziz1994@gmail.com \\ Tyas Santri \\ Fakultas Teknik, Program Studi Arsitektur \\ Universitas Langlangbuana \\ tyassantriarch@gmail.com
}

\author{
Alfred Wijaya \\ Fakultas Teknik, Program Studi Arsitektur \\ Universitas Langlangbuana \\ alfred.wijaya.arsitek@gmail.com
}

\begin{abstract}
Abstrak - Perkembangan e-sport di Indonesia semakin pesat. Mulai dari anak-anak hingga dewasa banyak yang menggandrungi e-sport, hal ini bisa terlihat dari semakin banyaknya pengunjung rental playstation untuk bermain game online. E-sport telah menjadi salah satu cabang olah raga dan sudah disahkan oleh KEMENPORA sejak tahun 2014. Pada tahun 2018 pada ajang ASIAN GAMES yang diselenggarakan di Jakarta-Palembang $e$ sport sudah mulai dipertandingkan. Dengan semakin berkembangnya e-sport maka dibutuhkan area atau fasilitas olah raga yang dapat mewadahi aktifitas atlit $e$ sport profesional maupun orang yang tertarik terjun di industri e-sport. Kajian ini merupakan proses merancang fasilitas yang dapat mewadahi aktifitas olah raga $e$-sport yaitu e-sport arena yang berlokasi di kota Bandung dengan penerapan arsitektur metafora. E-Sport arena ini sendiri bertujuan guna memfasilitasi dan mewadahi atlit e-sport professional untuk meningkatkan kemampuan di bidang e-sport baik untuk berlatih maupun bertanding, serta juga memberikan kesempatan bagi mereka yang tertarik terjun berprofesi di industri e-sport guna menjadi atlit professional. Melalui kajian perancangan e-sport arena ini diharapkan dapat memberikan masukan alternatif desain rancangan e-sport arena bagi pemerintah jika ingin membangun fasilitas olah raga e-sport dan bagi kalangan akademik untuk menambah referensi desain atau rancangan arsitektur e-sport arena.
\end{abstract}

Kata kunci - e-sport arena, game online, arsitektur metafora.

\section{PENDAHULUAN}

Semakin berkembangnya teknologi, kini video game bukan lagi sekedar game semata. namun video game telah beranjak menjadi profesional dan menjadi salah satu cabang olahraga resmi yaitu esport.

E-Sport merupakan kegiatan adu ketangkasan antar individu atau kelompok yang tidak terbatas hanya pada kegiatan fisik dan dilakukan dengan menggunakan suatu alat elektronik. Di Negara besar seperti China, USA, Eropa, perkembangan e-sport sudah sangat pesat bahkan mulai dijadikan cabang olahraga baru. Ekosistem e-sport semakin stabil bahkan bertambah seiring dukungan beragam kompetisi baik lokal maupun internasional yang menjadikannya sebuah industri baru.

Dikutip dari pikiran-rakyat.com, Asosiasi Penyelenggara Jasa Internet Indonesia (APJII) ini mengadakan survey tahunan tentang pengguna internet untuk bermain e-sport/ game online di Indonesia, dan hasil nya jumlah gamer di Indonesia saat ini diprediksi sudah mencapai 34 juta orang. Dari jumlah tersebut, 19,9 juta diantaranya adalah gamer online berbayar dan rata-rata pengeluarannya mencapai 9,12 dolar Amerika Serikat (AS).Dikutip dari ayobandung.com bahwa pemerintah Indonesia yang akhirnya mengakui secara resmi organisasi esport sebagai satu cabang olahraga yang diakui oleh Kementerian Pemuda dan Olahraga pada tahun 2014 silam. Namun minimnya fasilitas menjadi salah satu penyebab atlet Lokal dan Nasional kurang dapat bersaing di level Internasional. Di Kota Bandung sendiri juga sudah sering diadakannya kompetisi dan turnamen e-sport dari tingkat Kota dan Provinsi namun kompetisi e-sport diselenggarakan di tempat yang bukan peruntukannya seperti mall, cafe serta warnet. Pernah diadakannya liga e-sport tingkat SMU yaitu HSL (High School League) dimana tahun 2018 kemarin tim e-sport SMU 7 Bandung menjadi juara, dan di tahun 2019 kini Pemerintah juga mengadakan kompetisi liga e-sport yang diberi nama Piala Presdien. Berangkat dari menjamurnya kompetisi e-sport dan belum tersedianya arena khusus e-sport. Maka dari itu dibutuhkan fasilitas esport untuk mendukung skill atlit e-sport menjadi lebih baik dan mampu bersaing di level Intenasional. Dalam kajian ini akan mencoba merancang e-sport arena dengan penerapan arsitektur metafora yang berlokasi di kota Bandung. 


\section{METODE}

Kajian ini merupakan studi perancangan e-sport arena dengan penerapan arsitektur metafora dan lokasi tapak perancangan di Kota Bandung dengan menggunakan metode deskriptif analisis. Adapun tahapan-tahapannya adalah sebagai berikut:

1. Merumuskan tijauan pustaka terkait perancangan e-sport arena dengan penerapan arsitektur metafora

2. Mengidentifikasi dan menganalisis kondisi tapak

3. Proses perancangan desain melalui pertimbangan analisis untuk menghasilkan konsep desain dengan penerapan arsitektur metafora

Metafora dalam arsitektur menurut Geoffrey Broadbent, 1995 dalam buku "Design in Architecture" adalah satu metode kreatifitas yang ada pada desain spektrum sang perancang. Menurut Charles Jenks, dalam "The Language of Post Modern Architecture"metafora sebagai kode yang ditangkap pada suatu saat oleh pengamat, yang diperoleh dari suatu obyek dengan mengandalkan obyek lain. Misalnya bagaimana melihat suatu bangunan sebagai suatu yang lain karena adanya unsur yang mirip. Menurut Anthony C. Antoniades, 1990 dalam "Poethic of Architecture" metafora adalah suatu cara memahami suatu hal, seolah hal tersebut sebagai suatu hal yang lain sehingga bisa mempelajari pemahaman yang lebih baik dari suatu topik dalam pembahasan. Singkatnya adalah menerangkan suatu subyek dengan subyek lain dan berusaha melihat suatu subyek sebagai suatu hal yang lain. Arsitektur metafora merupakan gaya arsitektur yang mengambil bentuk dari kiasan atau perumpamaan dari sesuatu. Terdapat tiga kategori arsitektur metafora yaitu intangible metaphor (metafora abstrak), tangible metaphors (metafora konkrit) dan combined metaphors (metafora kombinasi). Dalam studi perancangan e-sport arena ini menggunakan tangible metaphors. Dimana tangible metaphors merupakan metafora nyata yang berangkat dari bentuk visual serta spesifikasi atau karakter tertentu dari sebuah benda nyata.

\section{HASIL DAN DISKUSI}

\subsection{Lokasi Tapak}

Lokasi tapak untuk perancangan e-sport arena terletak di jalan Soekarno-Hatta No.461, Pasirluyu, Regol, Kota Bandung, Jawa Barat 40254. Regulasi tapak menyesuaikan RTRW kota Bandung. Adapun data dan regulasi tapak adalah sebagai berikut:

Luas tapak: $12.122 \mathrm{~m}^{2}$; KDB : 70\% ; KLB : 5,6 ; $\mathrm{KDH}: 20 \%$; GSB : $15 \mathrm{~m}$.

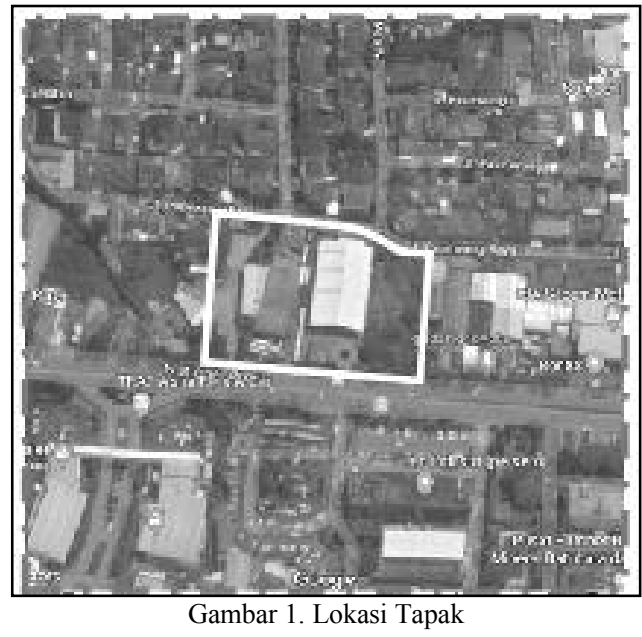

\subsection{Analisis Tapak}

\subsubsection{View Tapak}

Agar view diarea tapak terlihat lebih baik makan ruang luar atau plaza diarea depan dan belakang akan di desain dengan menggunakan beberapa ketinggian.

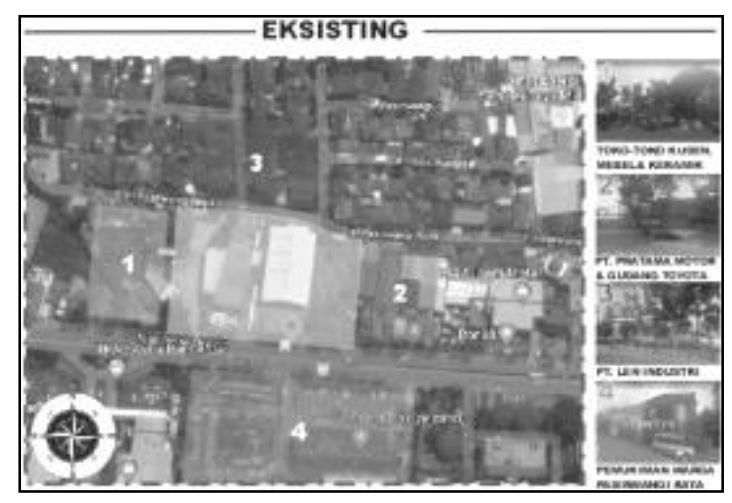

Gambar 2.Eksisting View Tapak

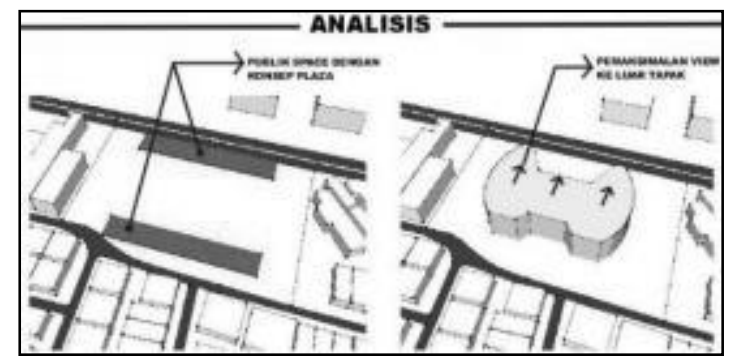

Gambar 3. Analisis View Tapak

\subsubsection{Aksesbilitas}

Berdasarkan kondisi eksisting aksesbilitas di rencanakan dengan akses pintu masuk dan keluar bangunan e-sport arena terpisah dan sirkulasi di dalam tapak mengelilingi bangunan e-sport arena. 


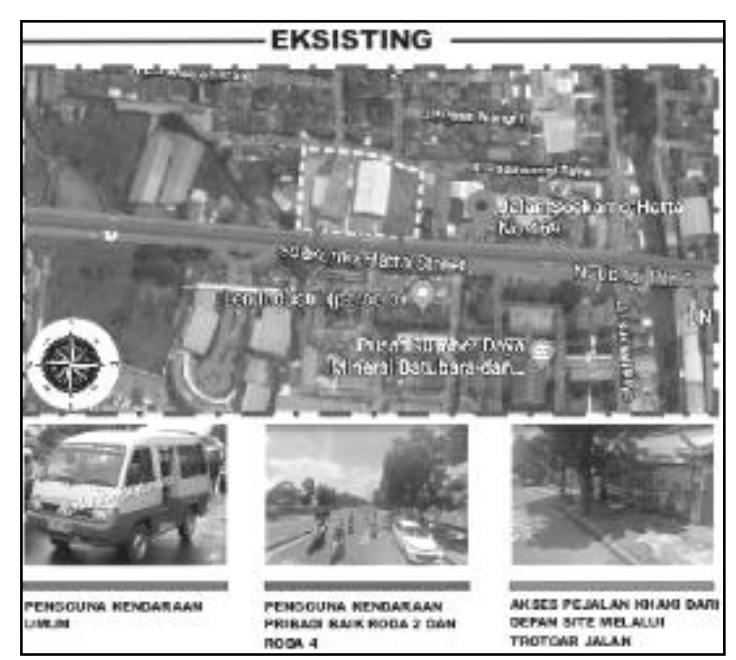

Gambar 4. Eksisting Aksesibilitas

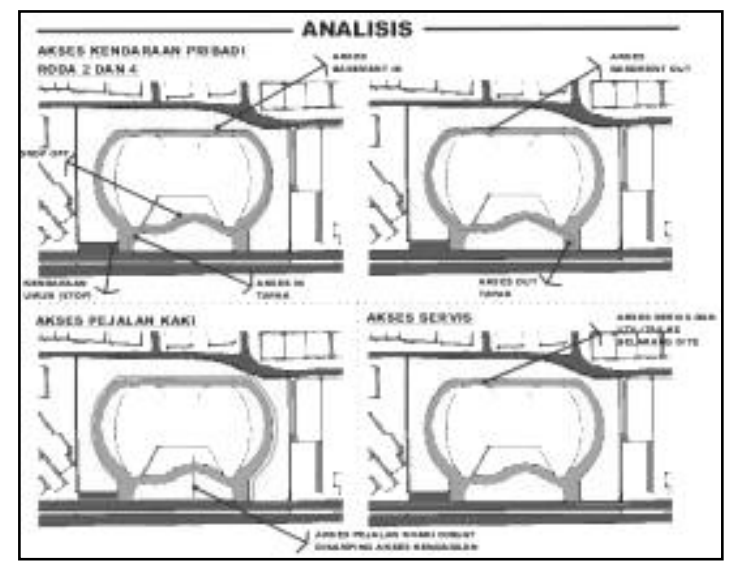

Gambar 5. Analisis Aksesibilitas

\subsubsection{Vegetasi}

Mempertahankan beberapa pohon yang sudah ada di area tapak, guna memberi hawa sejuk, dan menambah tanaman \& pohon sebagai pengarah akses sirkulasi di dalam tapak.

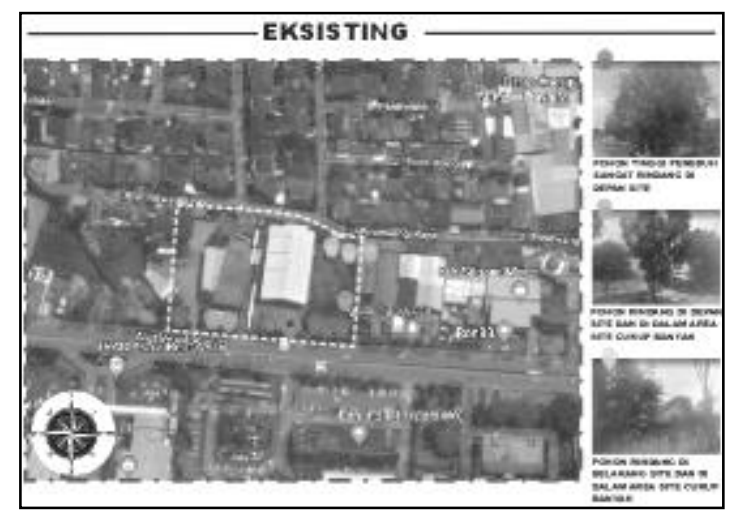

Gambar 6. Eksisting Vegetasi

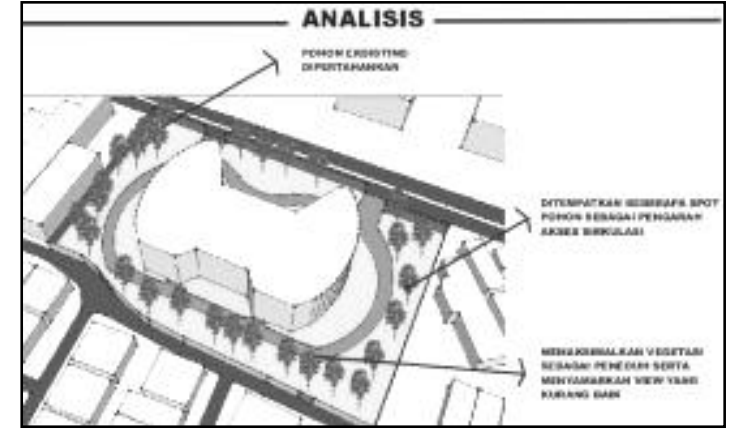

Gambar 7. Analisis Vegetasi

\subsubsection{Kebisingan}

Kebisingan direspon dengan memperbayak pohon pada area ruang luar bangunan dan bangunan e-sport arena didesain dengan adanya dinding massif dan sitem akustik agar suara bising dari luar tidak langsung masuk kedalam begitu juga sebalimya suara yang ditimbulkan dari dalam e-sport arena juga tidak langsung keluar.

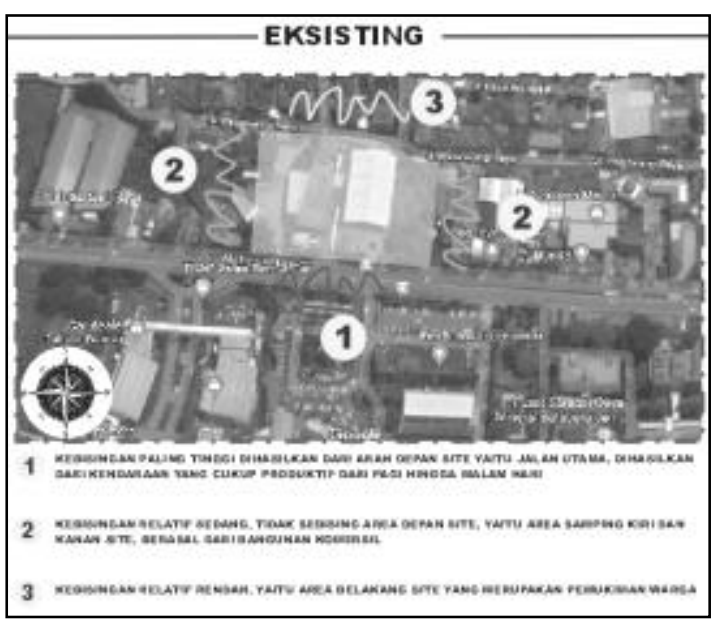

Gambar 8. Eksisting Kebisingan

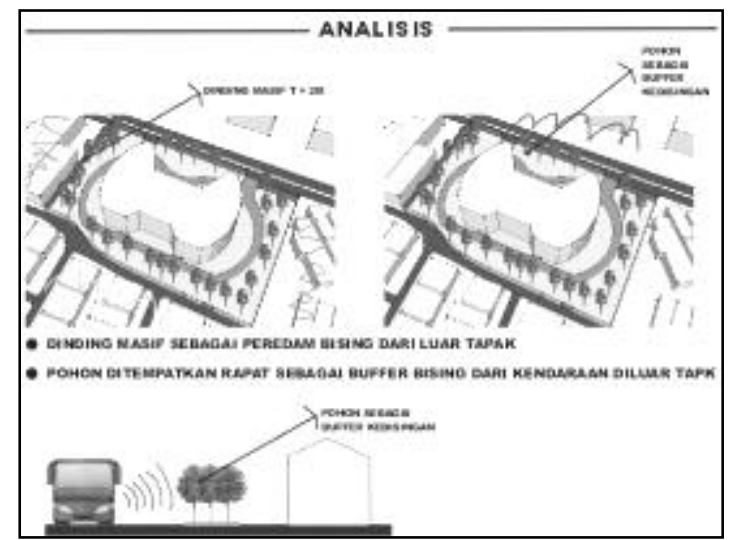

Gambar 9. Analisis Kebisingan 


\subsubsection{Pergerakan Angin}

Pergerakan angin yang terjadi di lokasi tapak dapat dimanfaatkan sebagai penghawaan alami pada bangunan dengan mendesain bukaan-bukaan pada fasad bangunan, dan hembusan angin agar tidak terlalu kencang dapat diminimalisir dengan adanya vegetasi pada ruang luar.

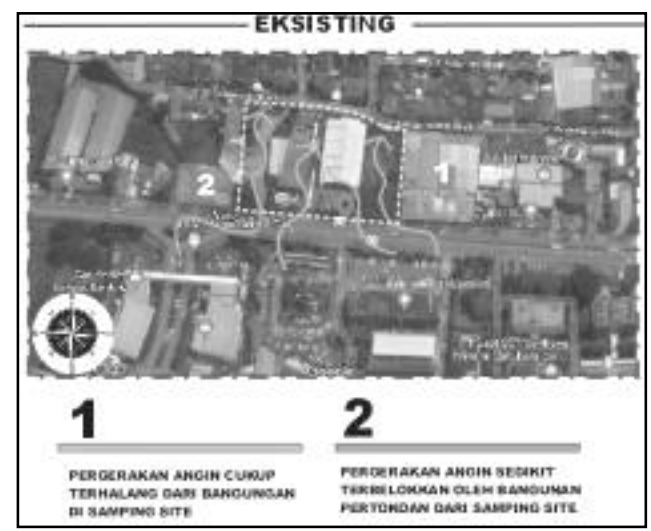

Gambar 10. Eksisting Pergerakan Angin

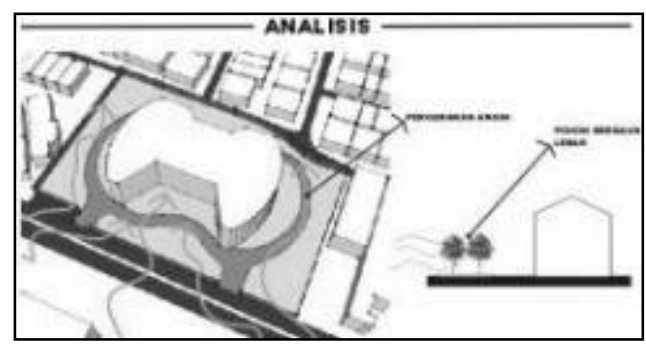

Gambar 11. Analisis Pergerakan Angin

\subsubsection{Pergerakan Matahari}

Berdasarkan kondisi eksisting bangunan menghadap kearah jalan utama dan cahaya matahari dimanfaatkan sebagai pencahayaan alami dengan mendesain bukaan pada fasad bangunan, agar panas matahari yang masuk dalam bangunan tidak terlalu panas diredam dengan reflective glass dan secondary skin.

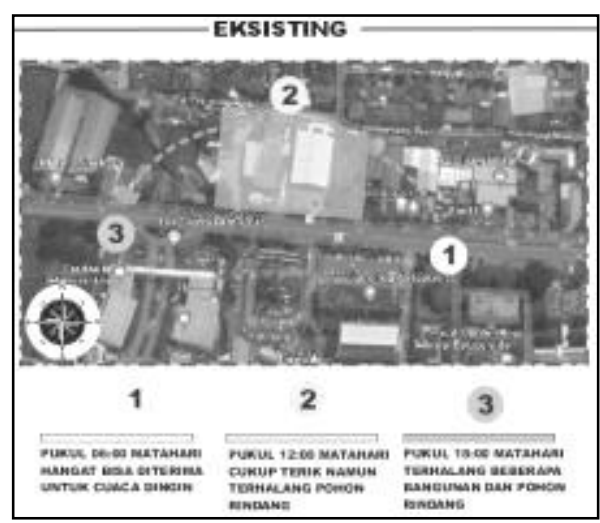

Gambar 12. Eksisting Pergerakan Matahari

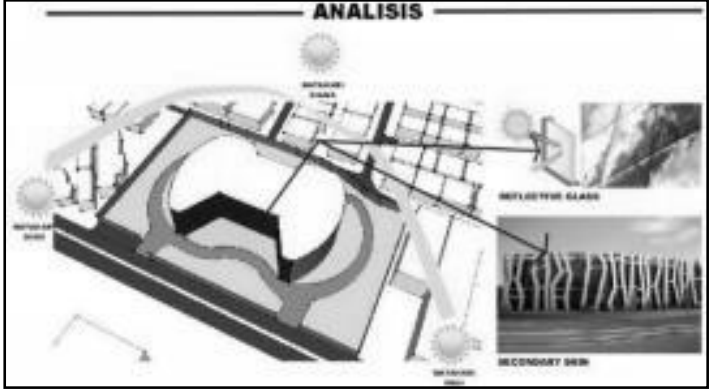

Gambar 13. Analisis Pergerakan Matahari

\subsection{Gubahan Massa}

Dalam studi perancangan bangunan e-sport arena ini metafora arsitektur salah satunya diterapkan pada gubahan massa bangunan, dimana gubahan massa bangunan merupakan transformasi bentuk dari joystick console gaming, yang mana joystick sendiri merupakan perangkat bermain game yang erat hubungannya dengan e-sport. Dengan penerapan arsitektur metafora yaitu metafora konkrit, diharapkan bentuk massa bangunan tidak hanya mewadahi segala aktifitas e-sport namun juga bentuk massa bangunan dapat mewakili dari aktifitas e-sport itu sendiri.

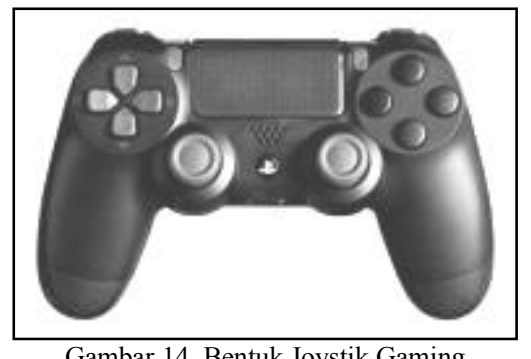

Massa bangunan terbentuk dari proses transformasi joystick yang mengalami subtraktif (pengurangan bentuk) dan additive (penambahan bentuk).

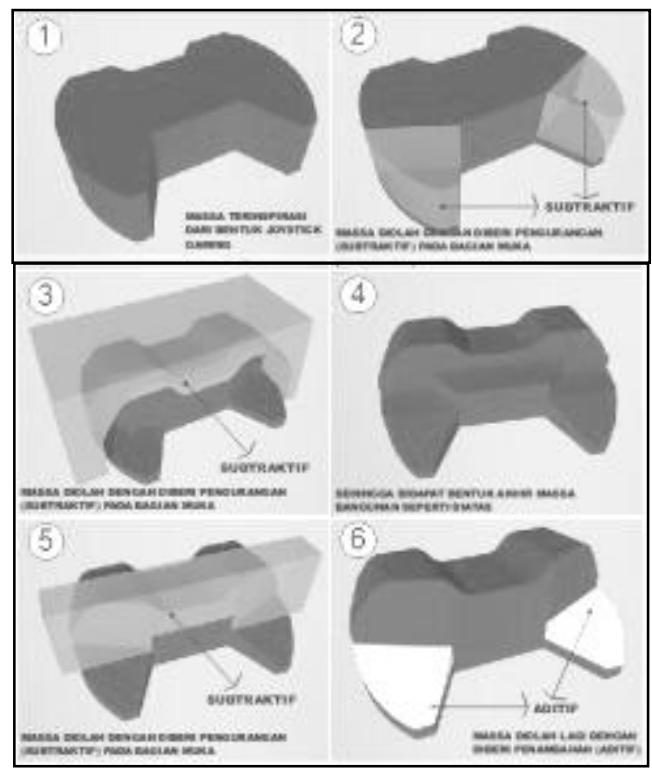

Gambar 15. Proses Transformasi bentuk Gubahan Massa Bangunan $E$ sport Arena 


\subsection{Hasil Desain}

\subsubsection{Desain Eksterior Bangunan}

Selubung bangunan e-sport arena dirancang menggunakan bahan ACP yang bertujuan untuk menutupi struktur space frame sedangkan pada facade bangunan menggunakan bahan ACP Cutting Laser yang difungsikan sebagai ornament bangunan.
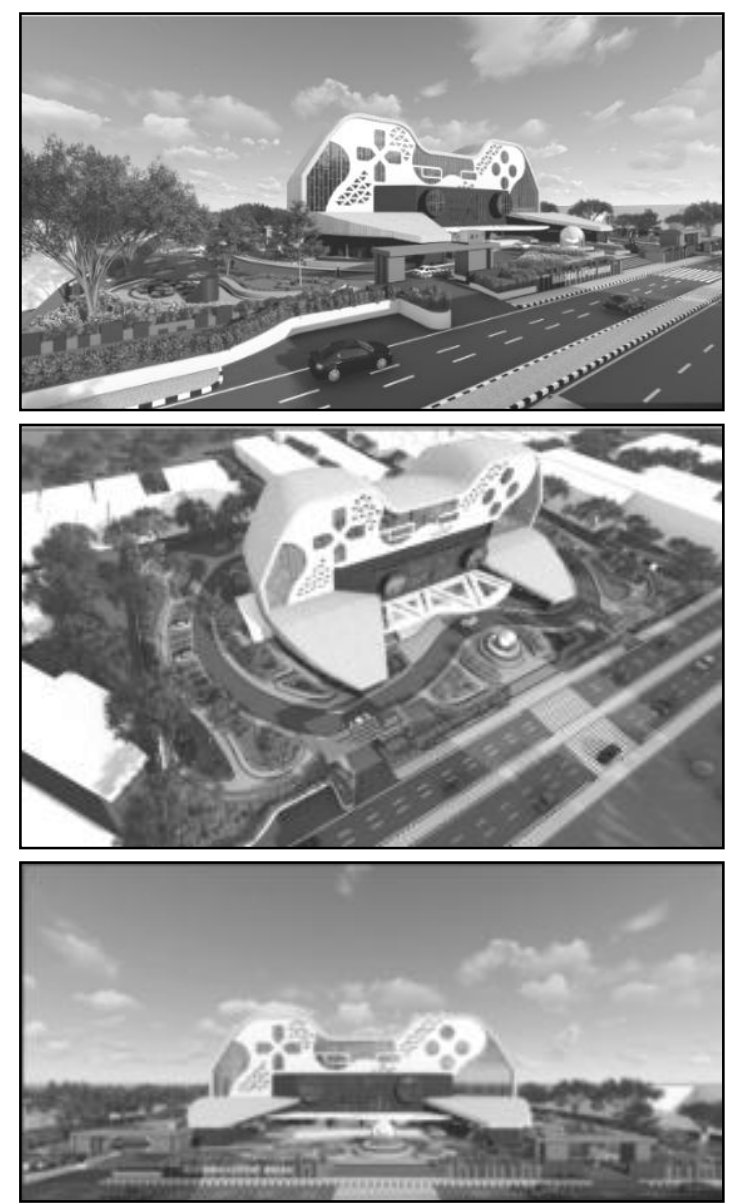

Gambar 16a. Perspektif dan Tampak Bangunan

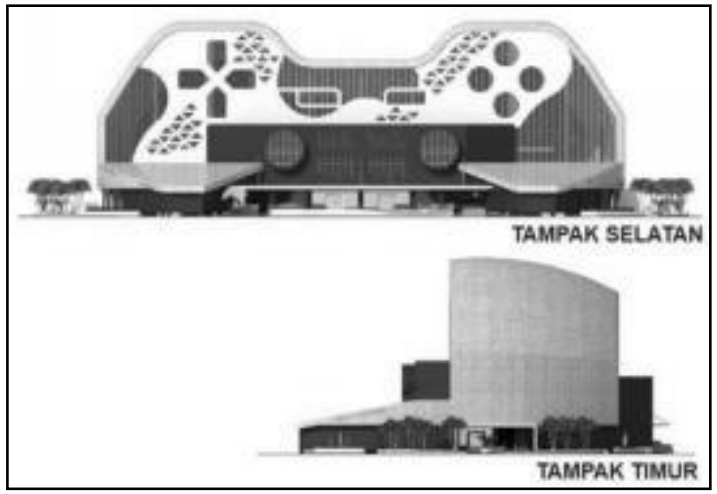

Gambar 16b. Perspektif dan Tampak Bangunan

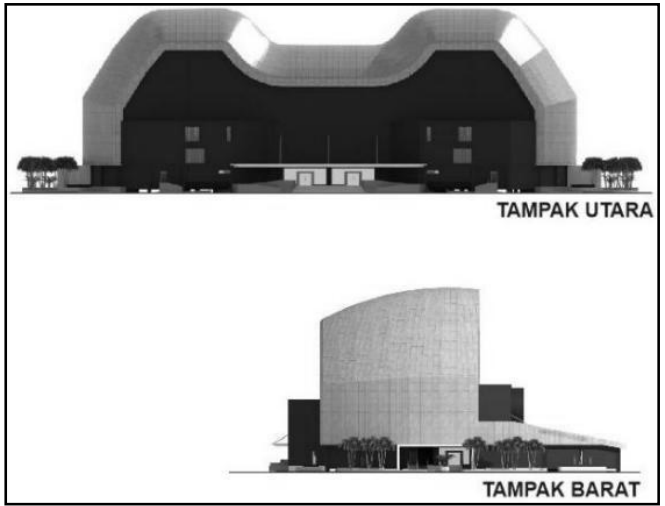

Gambar 16c. Perspektif dan Tampak Bangunan

\subsubsection{Entrance Utama}

Desain entrance utama merupakan metafora dari bawah pegangan joystik dari saat dilihat dari posisi depan.

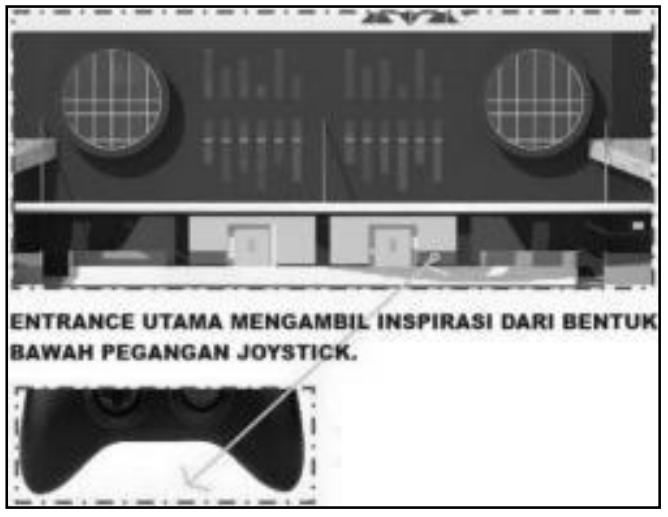

Gambar 17. Desain Entrance Utama

\subsubsection{Ornamen Facad}

Ornament pada facade e-sport arena didesain dengan penerapan metafora arsitektur dengan menggunakan secondary skin dari bahan ACP panel yang difabrikasi dengan bentuk menyerupai tombol pada joystick game, yang mana bertujuan sebagai penegas dari bentuk joystick, selain itu juga sebagai peredam panas serta mengurangi pencahayaan langsung pada ruang arena turnamen.

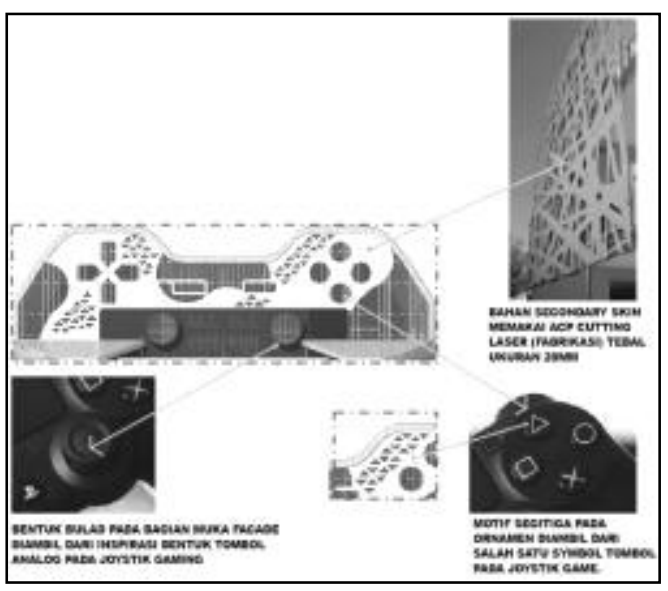

Gambar 18. Desain Ornamen Facad 


\subsubsection{Warna Facad}

Warna pada fasad bangunan e-sport arena ini dominan warna hitam dan putih, dimana warna dua warna ini merupakan salah satu varian warna dari joystick.

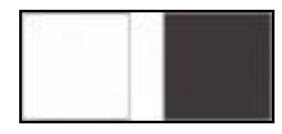

Gambar 19. Warna Facade

\subsection{Sirkulasi Bangunan}

\subsubsection{Sirkulasi Ruang Luar}

Sirkulasi ruang luar didesain merespon hasil analisis aksesbilitas dimana akses pintu masuk dan keluar bangunan e-sport arena terpisah dan sirkulasi di dalam tapak mengelilingi bangunan e-sport arena.
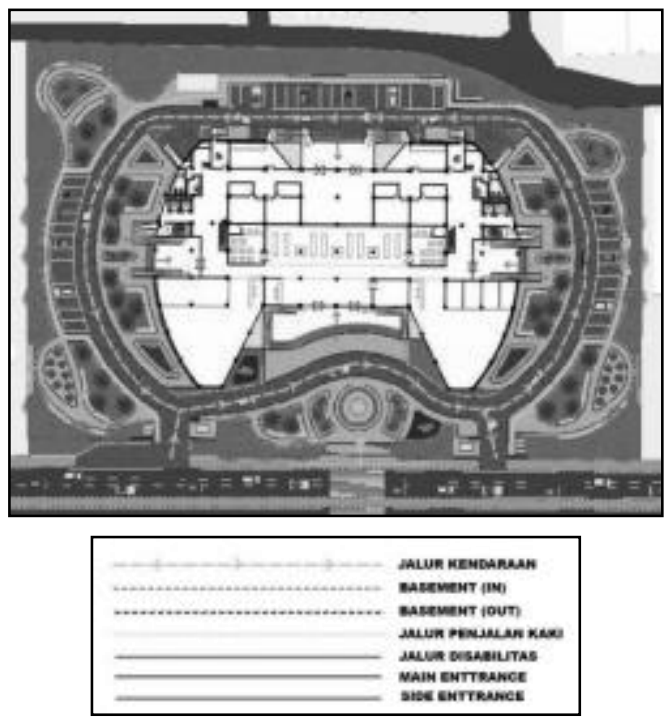

Gambar 20. Sirkulasi Ruang Luar Bangunan

\subsubsection{Sirkulasi Ruang Dalam}

Bangunan e-sport arena terdiri dari 3 lantai dan 2 basement dengan akses sirkulasi vertikal menggunakan lift, eskalator dan tangga.
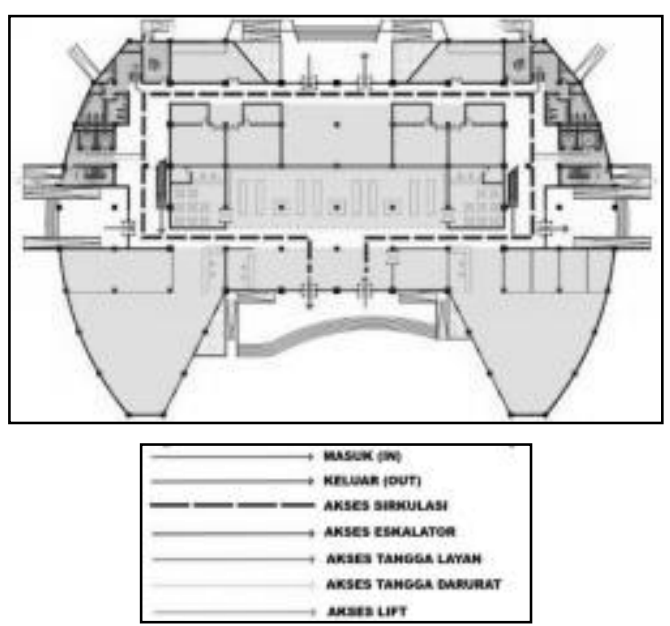

Gambar 21. Sirkulasi Ruang Dalam Bangunan (Lantai Dasar)

\subsection{Desain Interior Bangunan}

\subsubsection{Interior Ruang Console}

Pemilihan warna gelap pada dinding bertujuan untuk menonjolkan cahaya lampu LED pada Ruang console. Pada setiap satu layar game console disediakan 2 kursi dan 1 meja untuk 2 player yang bermain game. Penempatan meja dan kursi di tengah ruang diperuntukan untuk pengunjung yang hanya ingin sekedar menyaksikan player yang sedang bermain game console. Lampu LED pada plafon sendiri merupakan metafora dari jalur PCB yang berada pada komponen di dalam joystick, sehingga seakan akan memberi kesan berada di dalam joystick.

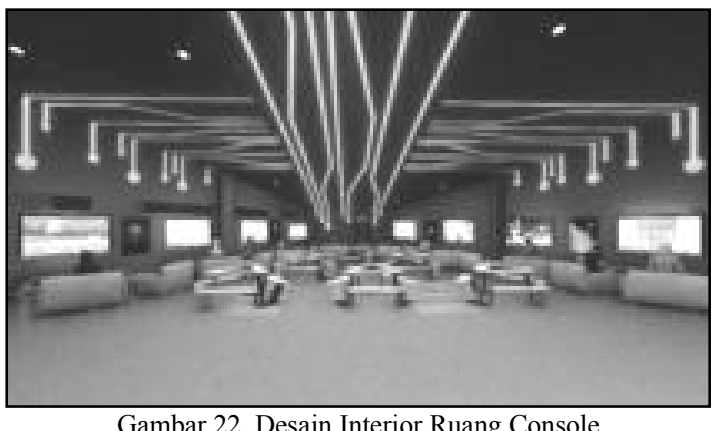

\subsubsection{Interior Ruang Arcade Game}

Pemilihan dinding bata expose berwarna putih pada ruang arcade game bertujuan untuk menonjolkan kesan retro pada ruang, dikarenakan game arcade cenderung didominasi game bersifat retro.

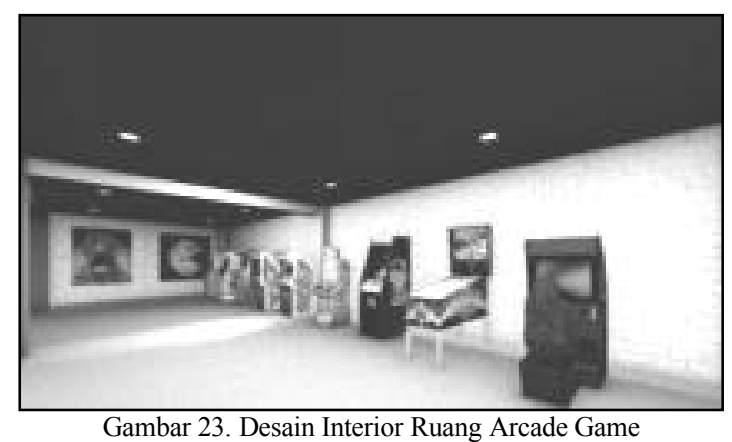

\subsubsection{Interior Ruang Team}

Ruang team berisikan 1 game desk dengan 10 kursi gaming dan $10 \mathrm{PC}$, hal ini dikarenakan team esport berformasikan 5 orang, sedangkan 5 orang lainnya sebagai player cadangan. 

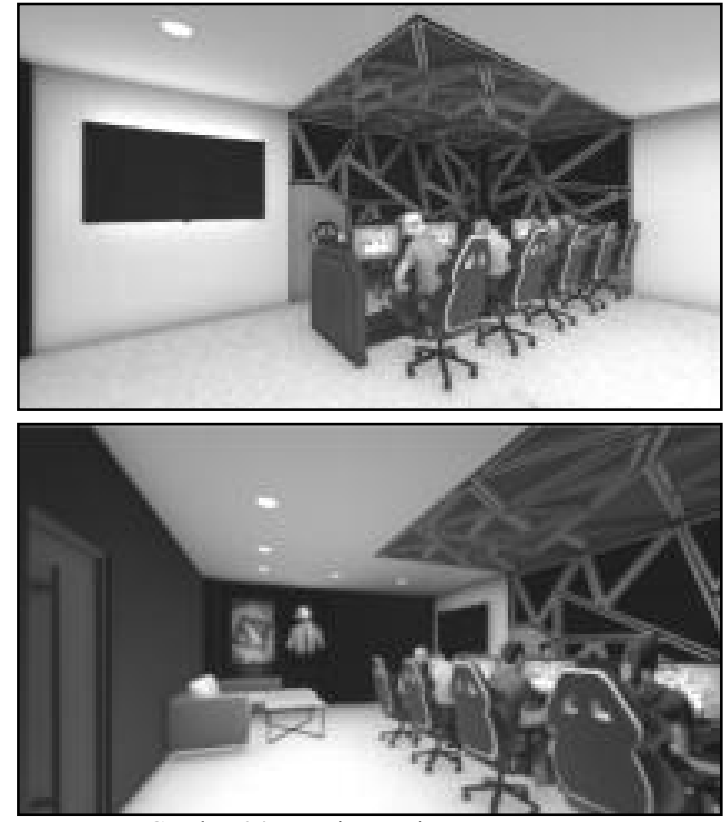

Gambar 24. Desain Interior Ruang Team

\subsubsection{Interior Galeri Game}

Ruang galeri game pada dasarnya memiliki konsep yang sama dengan ruang console game, namun dengan fungsi ruang yang berbeda dimana ruang galeri game difungsikan untuk pengunjung yang ingin bermain game e-sport dengan perangkat $\mathrm{PC}$, sehingga disediakan game desk berbentuk hexagon dengan 6 kursi gaming. Pemilihan game desk berbentuk hexagon sendiri bertujuan agar sirkulasi di dalam ruang galeri game lebih nyaman selain itu agar pengunjung yang bermain game PC mendapatkan kenyamanan secara privasi.

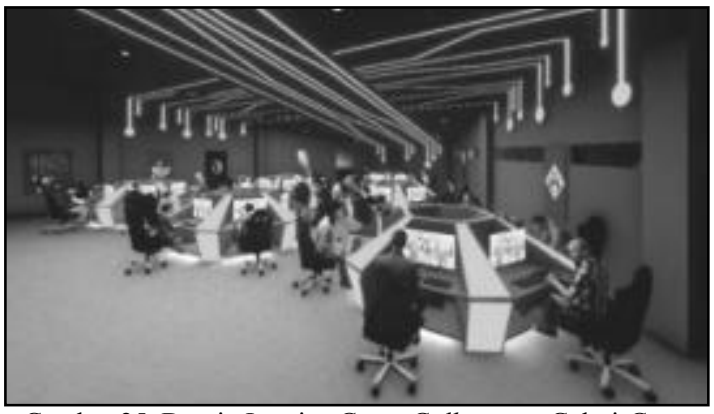

Gambar 25. Desain Interior Game Galleri atau Galeri Game

\subsubsection{Interior Ruang VR}

Pada ruang VR dibuat sekat partisi tiap ruang nya menjadi empat ruang, dengan tujuan agar player tidak bergerak terlalu bebas hingga keluar dari zona VR, layar monitor ditempatkan diatas ruang dengan terhubung langsung ke perangkat VR melalui CPU yang ditempatkan di meja depan Ruang VR.

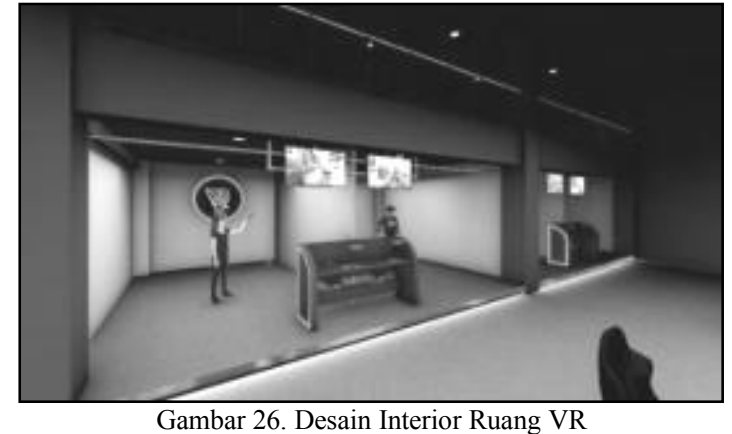

\subsubsection{Interior Turnamen Arena}

Pemilihan Warna dinding pada turnamen arena didominasi dengan warna gelap dengan tujuan menonjolkan layar display LED dan atlet yang bertanding sebagai focus utama dan juga memaksimalkan peran lampu sorot dan lampu LED pada ruang turnamen arena. Penambahan dekorasi pada dinding guna mengurangi kesan monoton pada dinding.
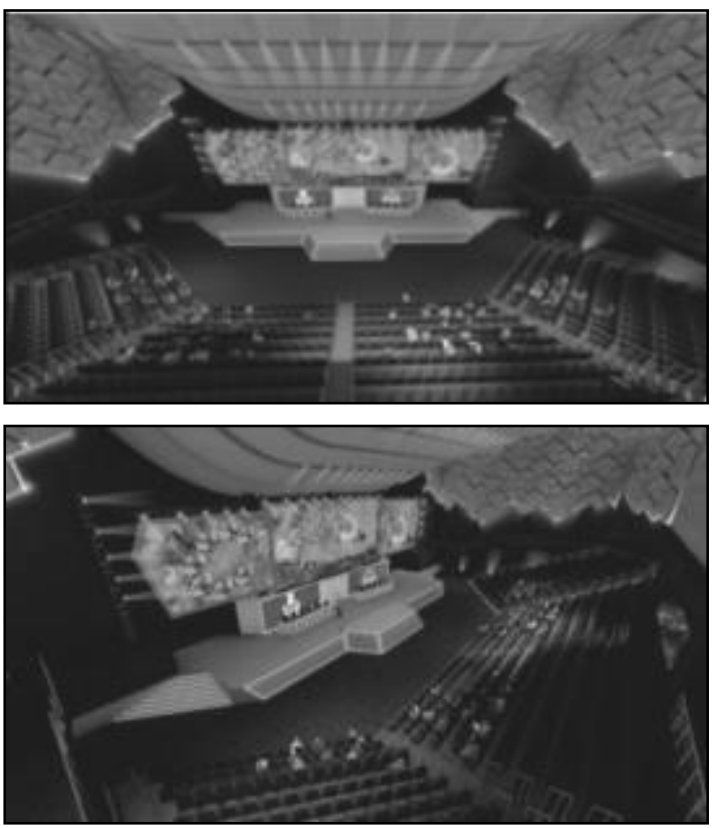

Gambar 27. DesainTurnamen Arena

\subsection{Konsep Ruang Luar}

\subsubsection{Desain Sclupture}

Sclupture pada area depan bangunan merupakan bentuk joystick dengan warna kuning perunggu merupakan metafora dari piala kemengangan bermain game. Sclupture pada area depan site, selain untuk menambah keindahan site yaitu juga untuk menjadi area photo spot untuk pengunjung di area site. 


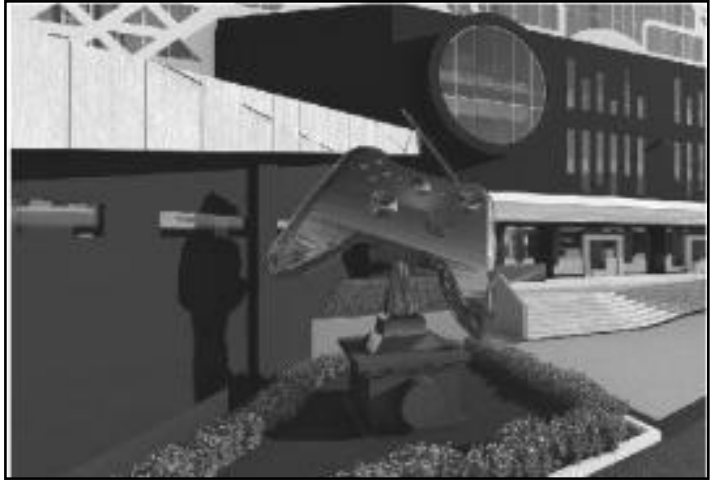

Gambar 28. Desain Sclupture

\subsubsection{Pos Jaga}

Bentuk kantor pos jaga merupakan metafora dari bentuk USB pada komputer, dengan tujuan agar bentuk pos jaga tidak berbentuk masif dan juga agar terlihat matching dengan bangunan e-sport arena merupakan transformasi dari joystick.

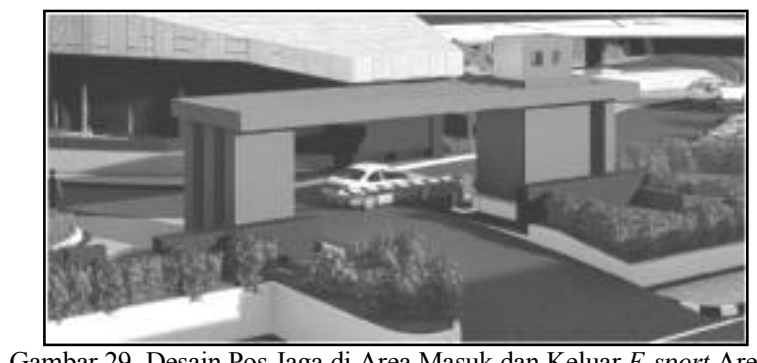

Gambar 29. Desain Pos Jaga di Area Masuk dan Keluar E-sport Arena

\subsubsection{Wifi Zone}

Wifi zone berada pada area depan bangunan tepatnya di sebelah kanan dan kiri bangunan. Wifi zone di rencanakan sebagai area santai pengunjung diluar bangunan bisa sambil bermain game di handphone dengan menggunakan fasilitas wifi.

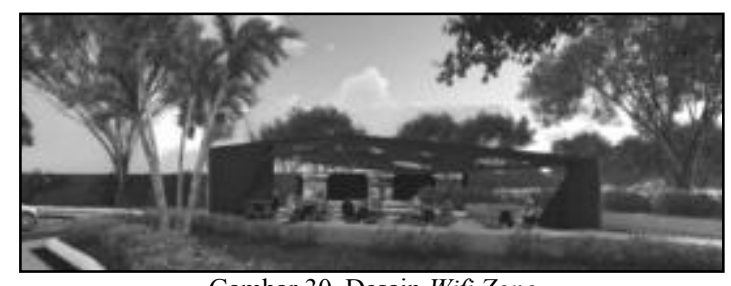

Gambar 30. Desain Wifi Zone

\subsubsection{Parkir Sepeda}

Selain parkir mobil dan motor juga terdapat area parkir untuk sepeda untuk pengunjung yang datang menggunakan sepeda, area parkir sepeda berada di sisi belakang bangunan.

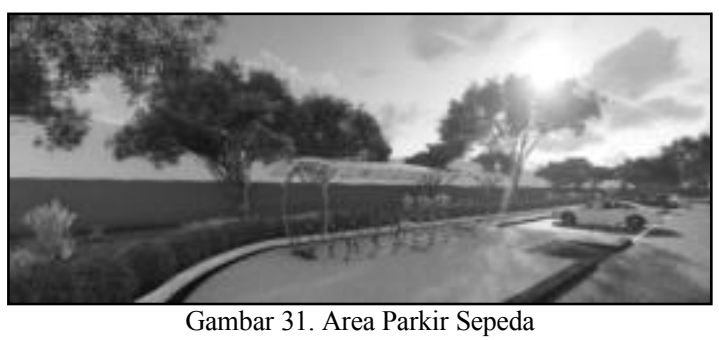

\subsubsection{Titik kumpul kebakaran}

Titik Kumpul kebakaran berada di setiap sisi raun luar bangunan yaitu sisi kiri dan sisi kanan belakang banguna dan depan bangunan, Pemilihan lokasi titik kumpul didasari dari arah tempat pintu keluar dari tangga darurat pada bangunan, supaya dapat langsung terlihat setelah keluar dari pintu darurat. Dan juga jarak antara bangunan dan titik kumpul kebakaran mesti agak berjauhan. Di bagian pagar belakang bangunanan juga terdapat pintu darurat yang langsung menuju jalan di permukiman belakang untuk antisipasi jika terjadi kebakaran pengunjung yang lari kearea titi kumpul belakang bisa langsung keluar melalui pintu ini, sedangkan yang lari ke area titik kumpul depan dapat langsung keluar ke jalan utama yaitu jalan Soekarno-Hatta.

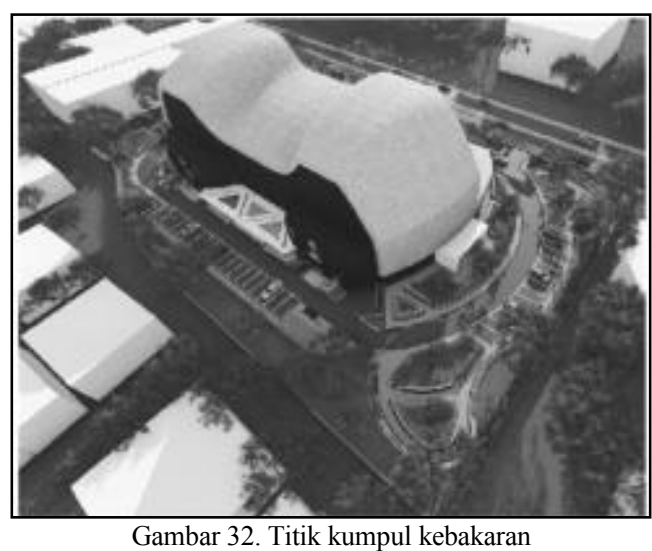

\subsection{Struktur Bangunan}

\subsubsection{Sub Struktur}

Dinding penahan tanah (DPT) Jenis cantilever retaining wall memakai bahan beton bertulang. Pondasi bangunan menggunakan pondasi tiang pancang untuk menopang beban bangunan, dimana bangunan e-sport arena memiliki beban mati dan hidup yang cukup banyak saat event perlombaan esport.

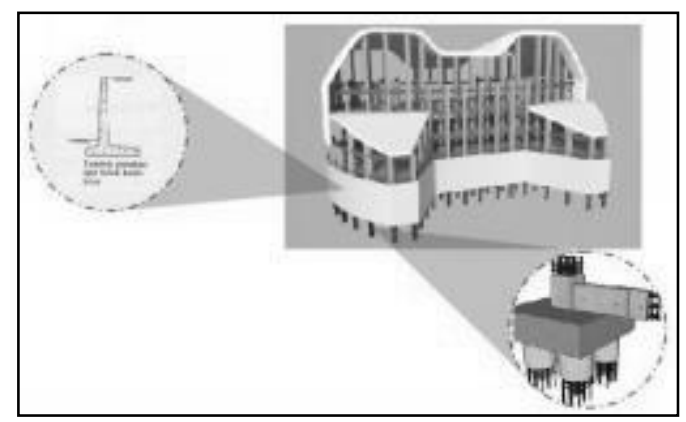

Gambar 33. Sub Struktur

\subsubsection{Upper Struktur}

Kepala bangunan memakai rangka baja space frame dikarenakan diperlukannya ruang luas bebas kolom di arena turnamen (struktur bentang lebar). Badan bangunan memakai rigid frame (rangka kaku). 


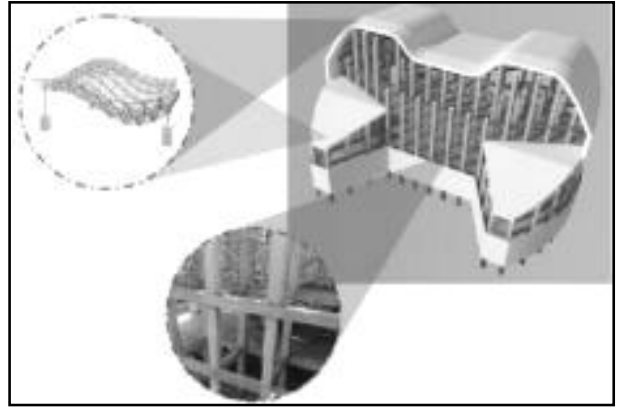

Gambar 34. Upper Struktur

\subsection{Utilitas}

\subsubsection{Sistem Kelistrikan}

Sistem kelistrikan pada gedung e-sport arena ini, berdasarjan asumsi mengenai kebutuhan daya listrik yang tinggi, sehingga sumber daya pada gedung ini berasal dari gardu PLN sendiri kemudian di distribusi ke ruang panel / ME yang nanti disebarkan melalui panel-panel per lantai dari gedung e-sport ini.

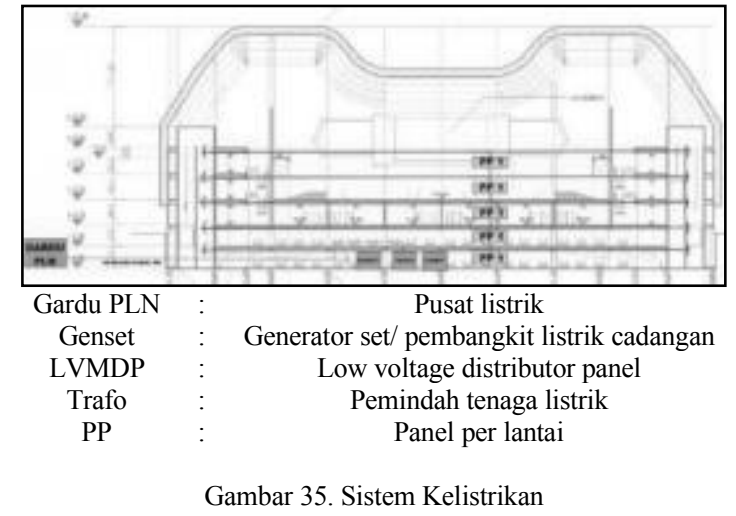

\subsubsection{Sistem Air Bersih}

Sistem Air bersih, bersumber dari PDAM yang kemudian di distribusi ke ruang bak penampumpangan yang dibagi 2 yaitu air bersih dan hydrant lalu tersalurkan menuju ruang pompa dan di distribusi masing- masing ke roof tank lalu menuju $\mathrm{KM} / \mathrm{WC}$ dan ke IHB juga menuju ke hydrant pilar.

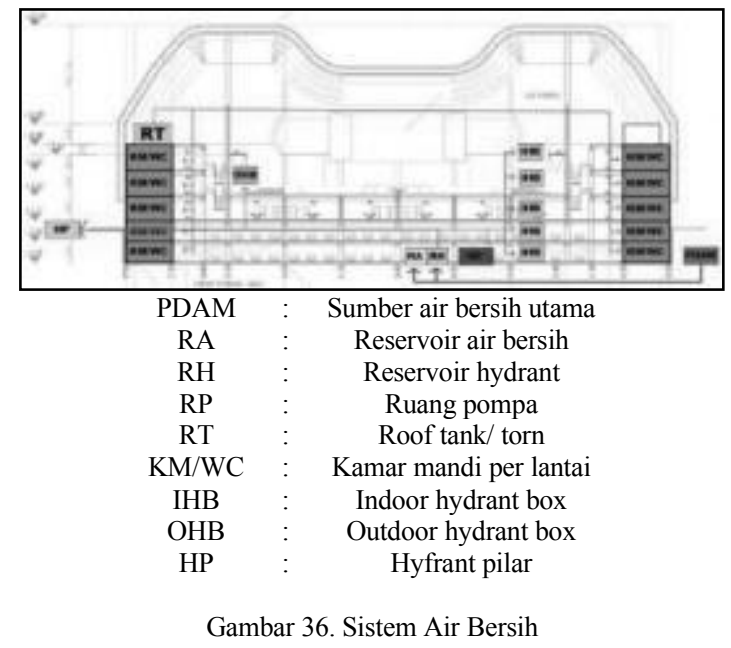

\subsubsection{Sistem Air Kotor}

Sistem air kotor pada bangunan ini, didistribusi langsung dari semua sumber baik grey water maupun black water dari seluruh kamar mandi menuju ke STP yang kemudian diarahkan menuju saluran kota.

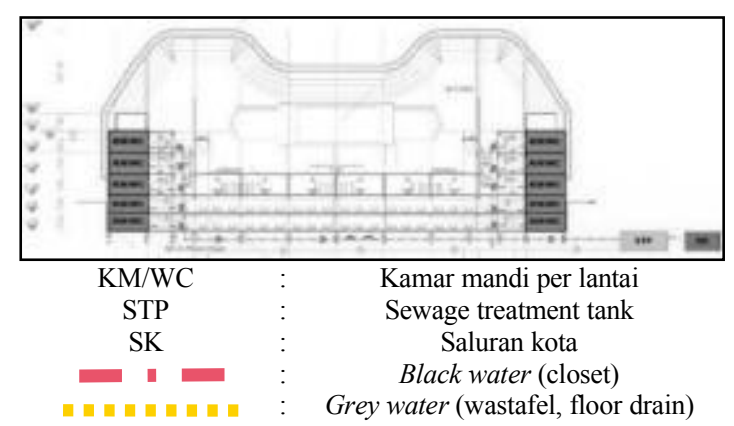

Gambar 37. Sistem Air Kotor

\subsubsection{Sistem Air Hujan}

Sistem pembuangan air hujan pada bangunan ini disalurkan ke talang air kemudian meunuju saluran air hujan di sekeliling bangunan yang nantinya disalurkan ke sumur resapan.

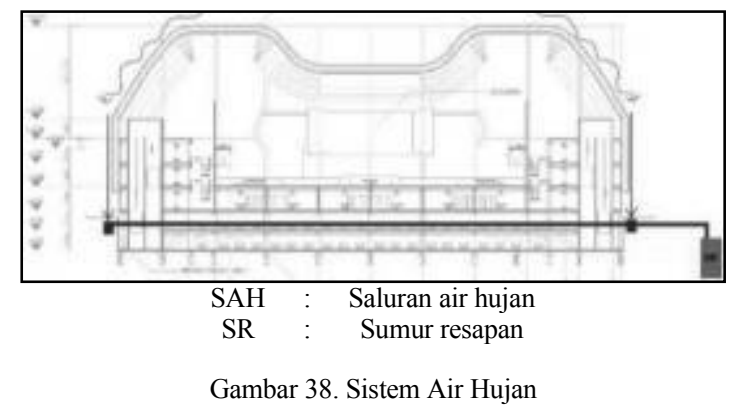

\section{KESIMPULAN}

Penerapan arsitektur metafora konkrit pada studi perancangan bangunan e-sport arena ini teraplikasikan pada desain eksterior (gubahan massa, fasad bangunan) maupun desain interior bangunan. Bangunan e-sport arena di desain dengan menerapkan arsitektur metafora konkrit dengan mentranformasikan bentuk joystick menjadi bentuk massa bangunan dan fasad bangunan e-sport arena. Bentuk massa dan fasad bangunan yang menyerupai joystick diharapkan dengan mudah deikenali oleh masyarakat sebagai bangunan gedung e-sport arena serta dapat menjadi daya tarik tersendiri bagi pengunjung yang berkunjung ke bangunan e-sport arena, selain itu diharapkan desain bangunan e-sport arena ini dapat menjadi icon baru kota dan menjadi dayatarik baru bagi wisatawan yang berkunjung ke kota Bandung. 


\section{DAFTAR PUSTAKA}

[1] Ai Rika Rachmawati. "Gamer Indonesia Diprediksi Capai 34 Juta Orang”. https:/www.pikiran-rakyat.com/ekonomi/2018/ 08/06/gamer-indonesia-diprediksi-capai-34juta-orang-428379 (diakses 8 Maret 2019).

[2] Asri Wuni Wulandari. "Immortal, Satu-satuya Game Center Center bertaraf Internasional di Bandung". https:/www.ayobandung.com/read /2017/03/ 12/17570/immortal-satu-satunyagame-center-bertaraf-internasional-di-bandung (diakses 8 Maret 2019).

[3] Bappeda Kota Bandung. "Rencana Tata Ruang Wilayah Kota Bandung Tahun 2011-2031". Kota Bandung. 2011.

[4] Bechthold, Martin. "Innovation Surface Structure: Technology and Application". New York: Taylor \& Francis. 2008.

[5] Burris-Meyer, Harold, Edward C Cole. 1949. Theaters \& Auditoriums. The Van Rees: USA

[6] Chihara, J.D., J. H. Callender. 1973. TimeSaver Standards for Building Types. USA

[7] Daniel L. Schodek, Structures, cetakan pertama, 1991 (Eresco), cetakan kedua, 1995 (Eresco), cetakan ketiga, 1998, (Refika).

[8] D.K Ching, Francis. "Alih bahasa In Nurahma Tresani Harwadi, Arsitektur, Bentuk, Ruang dan Tatanan", edisi kedua, Penerbit Erlangga, Jakarta. 2000.

[9] Henri. "Jenis-Jenis Struktur Pondasi". https://asearsitek.wordpress.com/2013/09/30/jen is-jenis-struktur-pondasi/ (diakses 14 Maret 2019).

[10] Julio. "E-Sport Arena Berstandar Internasional di Badung”. Bali. Universitas Udayana. 2016.

[11] Muhammad Setiawan, Perancangan Gedung Convention Hall Tema Exsplorasi struktur bentang lebar, Universitas Langlangbuana, 2018

[12] Neufert, Ernst. "Data Arsitek", Edisi 33 jilid 1, Erlangga, Jakarta. 1997.

[13] Neufert, Ernst. "Data Arsitek", Edisi 33 jilid 2, Erlangga, Jakarta. 1997.

[14] Poerwadarminta W.J.S. "Kamus Umum Bahasa Indonesia”, PN Balai Pustaka, Jakarta. 1976.

[15] Santri, T. , 2018 , Analisis Karakteristik Visual Arsitektur Pemukiman Nelayan. Jurnal Tiarsie, 15(2), 55-60.

[16] Wijaya, A., \& Sari, S. O. , 2018. Penataan Jalur Pedestrian Berbasis Transit Oriented Development pada Revitalisasi Kawasan Stasiun Kereta Api. Jurnal Tiarsie, 15(2), 39-44. 